\title{
Respiratory syncytial virus: current and emerging treatment options
}

This article was published in the following Dove Press journal:

ClinicoEconomics and Outcomes Research

25 April 2014

Number of times this article has been viewed

\author{
Tiffany L Turner' \\ Benjamin T Kopp' \\ Grace Paul' \\ Lindsay C Landgrave ${ }^{2}$ \\ Don Hayes J $r^{\prime}$ \\ Rohan Thompson' \\ 'Department of Pediatrics, \\ Ohio State University College \\ of Medicine, ${ }^{2}$ Clinical Pharmacy, \\ Nationwide Children's Hospital, \\ Columbus, $\mathrm{OH}$, USA
}

Correspondence: Tiffany L Turner Department of Pediatrics, Ohio State University College of Medicine, Nationwide Children's Hospital, 700 Children's Drive, Columbus $43205, \mathrm{OH}$, USA

$\mathrm{Tel}+\mathrm{I} 6147224766$

Fax +I 6147224755

Email tiffany.turner@nationwidechildrens. org

\begin{abstract}
Respiratory syncytial virus (RSV) is an important respiratory pathogen in infants and children worldwide. Although RSV typically causes mild upper respiratory infections, it frequently causes severe morbidity and mortality, especially in premature infants and children with other chronic diseases. Treatment of RSV is limited by a lack of effective antiviral treatments; however, ribavirin has been used in complicated cases, along with the addition of intravenous immune globulin in specific patients. Vaccination strategies for RSV prevention are heavily studied, but only palivizumab (Synagis ${ }^{\circledR}$ ) has been approved for use in the United States in very select patient populations. Research is ongoing in developing additional vaccines, along with alternative therapies that may help prevent or decrease the severity of RSV infections in infants and children. To date, we have not seen a decrement in RSV morbidity and mortality with our current options; therefore, there is a clear need for novel RSV preventative and therapeutic strategies. In this review, we discuss the current and evolving trends in RSV treatment for infants and children.
\end{abstract}

Keywords: bronchiolitis, lower respiratory tract infection, respiratory syncytial virus, probiotics, vitamin D

\section{Introduction}

Respiratory syncytial virus (RSV) is a negative-sense, single stranded RNA virus and a member of the Paramyxoviridae family. ${ }^{1}$ The viral envelope of RSV contains three proteins, the $\mathrm{G}$ glycoprotein, fusion protein, and small hydrophobic protein. ${ }^{1}$ The fusion protein is responsible for fusion, cell entry, and forming syncytia (Figure 1). ${ }^{1}$ The G protein functions in attachment to the host cell while the small hydrophobic protein's function has not yet been completely elucidated. ${ }^{1}$

\section{Epidemiology}

RSV is ubiquitous in terms of disease exposure, with nearly all children having been exposed by 2 to 3 years of age. ${ }^{1}$ The clinical scenario that results from RSV infection is typically a mild upper respiratory tract illness, but in infants and young children it can cause bronchiolitis, a lower respiratory tract infection (LRTI) characterized by wheezing, coughing, and respiratory distress. ${ }^{1}$ Children $<1$ year of age are at the highest risk of severe RSV manifestations, including hospitalization and death. ${ }^{1}$

While RSV is a global infectious agent, there is a clear seasonal variation in North American RSV incidence as reported by the Centers for Disease Control and Prevention (Figure 2). During 2011-2012 the RSV season ranged from late October to mid-January, and season offset ranged from early March to early May, which 

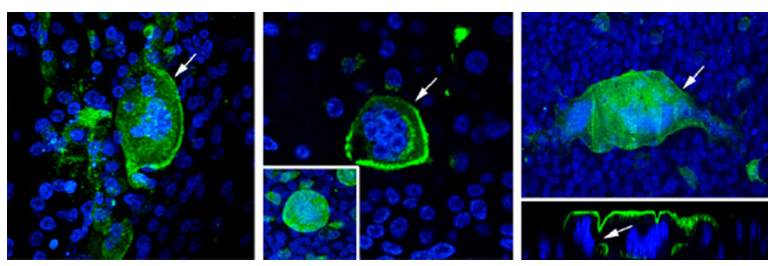

Figure I RSV causing syncytia formation.

Notes: Green indicates RSV infecting pediatric bronchial epithelial cells; blue indicates nuclei; arrows indicate syncytial formation. Reproduced from Villenave R, Thavagnanam S, Sarlang $S$, et al. In vitro modeling of respiratory syncytial virus infection of pediatric bronchial epithelium, the primary target of infection in vivo. Proc Natl Acad Sci USA. 20 I 2; 109( I3):5040-5045. ${ }^{61}$

Abbreviation: RSV, respiratory syncytial virus.

is consistent with previous years, except Florida, where RSV season has an earlier onset and longer duration. ${ }^{2}$ On average each year in the United States, RSV infection leads to 132,000 to 172,000 hospitalizations among children $<5$ years of age, 100,000 to 126,000 hospitalizations among children $<1$ year of age, and 1.5 million outpatient visits among children $<5$ years of age. ${ }^{3}$

RSV has been estimated to cause nearly 34 million episodes of acute LRTIs yearly, with 3.4 million episodes severe enough to require hospitalization worldwide. ${ }^{4}$ Of those hospitalized, an estimated 66,000 deaths related to RSV occur yearly, especially children $<2$ years of age and those in developing countries. Other children at risk of acquiring severe RSV disease include those with congenital heart disease, congenital lung malformations, chronic lung disease, and neuromuscular disease. Additional risk factors for hospitalization include age $<6$ months, male sex, siblings living in the household, daycare attendance, and exposure to tobacco smoke. ${ }^{4}$ Finally, irrespective of RSV severity, many studies have demonstrated a long-term impact of RSV LRTI upon children leading to a higher risk of asthma development. ${ }^{5,6}$

The management of acute RSV bronchiolitis is typically supportive. When hospitalization is required, supplemental oxygen for hypoxemia and intravenous (IV) fluids for dehydrated or poorly feeding infants may be indicated. There have been numerous studies evaluating the role of bronchodilators (albuterol, nebulized racemic epinephrine) and systemic corticosteroids in the treatment of bronchiolitis; however, routine use of these therapies has not been shown to be effective for the majority of children. ${ }^{7-11}$ In this article, we discuss the current consensus statement on the treatment of children with RSV by the American Academy of Pediatrics (AAP), review currently available therapies used in the treatment of RSV, and explore evolving treatment options.

\section{Management of RSV infection}

The AAP has developed guidelines on RSV and bronchiolitis (Table 1), which focus on both preventative and treatment measures. Analyses of various studies have shown no consensus among physicians worldwide regarding the diagnosis

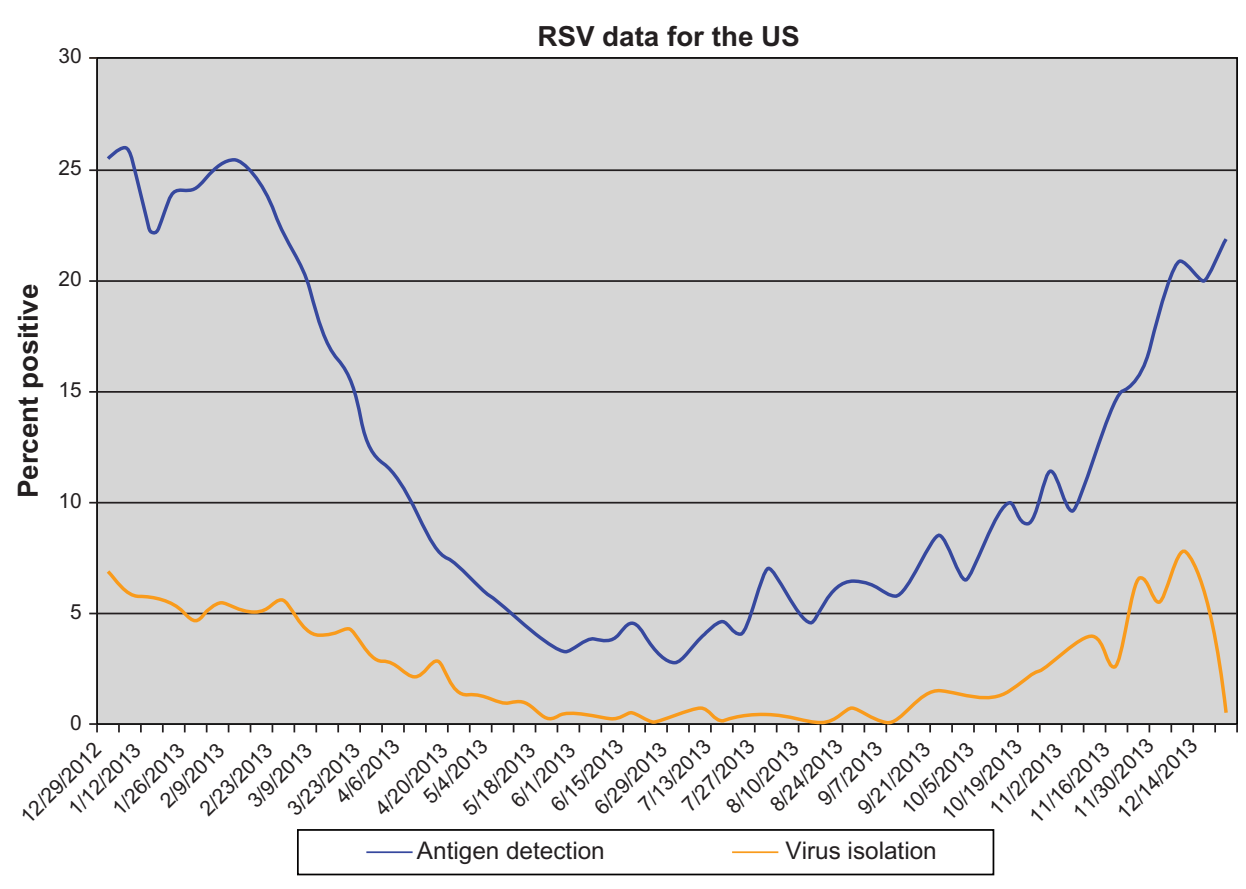

Figure 2 Weekly average laboratory test results from the Centers for Disease Control and Prevention collected on a voluntary basis. Note: Reprinted with permission from the Centers for Disease Control and Prevention. ${ }^{\prime \prime}$ 
Table I Bronchiolitis guidelines by the American Academy of Pediatrics

\begin{tabular}{|c|c|c|}
\hline Therapy & AAP recommendation & $\begin{array}{l}\text { Evidence } \\
\text { level }\end{array}$ \\
\hline $\begin{array}{l}\text { Inhaled bronchodilators } \\
\text { (ie, albuterol, nebulized } \\
\text { epinephrine) }\end{array}$ & $\begin{array}{l}\text { Should not be routinely used; } \\
\text { can consider trial and continue } \\
\text { only if clinical response }\end{array}$ & B \\
\hline Corticosteroids & Should not be routinely used & B \\
\hline Ribavirin & Should not be routinely used & B \\
\hline Palivizumab prophylaxis & $\begin{array}{l}\text { Should be given to select infants } \\
\text { (premature infants }<35 \text { weeks } \\
\text { gestation, children with } \\
\text { congenital lung or heart disease) }\end{array}$ & $A$ \\
\hline $\begin{array}{l}\text { Antibacterial } \\
\text { medications }\end{array}$ & $\begin{array}{l}\text { Should only be used in children } \\
\text { with documented comorbid } \\
\text { bacterial infection }\end{array}$ & B \\
\hline Oral or IV fluids & $\begin{array}{l}\text { Should assess hydration status } \\
\text { and provide fluids accordingly }\end{array}$ & $x$ \\
\hline Chest therapy & Should not be routinely used & B \\
\hline Oxygen & $\begin{array}{l}\text { Indicated if oxygen saturations } \\
\text { are persistently }<90 \% \text { in } \\
\text { room air }\end{array}$ & $\mathrm{D}$ \\
\hline
\end{tabular}

Notes: Evidence levels: A, well-designed randomized controlled trial (RCT) on relevant population; $\mathrm{B}, \mathrm{RCT}$ with minor limitations; $\mathrm{C}$, observational studies; $\mathrm{D}$, expert opinion, case reports; $\mathrm{X}$, exceptional situations where there is clear evidence of benefit or harm. Data from the American Academy of Pediatrics Subcommittee on Diagnosis and Management of Bronchiolitis. ${ }^{12}$

Abbreviations: AAP, American Academy of Pediatrics; IV, intravenous.

and treatment of this disorder. As a result, the AAP in 2006 published a consensus statement regarding the diagnoses and management of bronchiolitis. ${ }^{13}$

Management of bronchiolitis varies widely, from the use of bronchodilators (alpha and beta adrenergic agents), corticosteroids, antiviral therapies such as ribavirin, antibiotics, supplemental oxygen, and airway clearance.

The AAP consensus statement regarding the management of bronchiolitis in otherwise normal, healthy children does not recommend the routine use of bronchodilators in the treatment of bronchiolitis. A carefully monitored trial of these agents with documented positive clinical response using objective measures can be considered. If the trial is successful, then continued utilization of these agents during the illness would be warranted for select patients. Another common agent utilized is systemic corticosteroids. In concordance, the AAP does not recommend the routine use of systemic or inhaled corticosteroids in the management of bronchiolitis.

A variety of studies have been done using airway clearance measures such as vibration and percussion techniques, but these techniques have not shown clinical benefit. As a result, the AAP does not recommend the routine use of chest physiotherapy in the management of patients with bronchiolitis. ${ }^{13}$
Supplemental oxygen is indicated if the oxygen saturation falls persistently below $90 \%$ in otherwise previously healthy infants to maintain saturations $>90 \%$.

As bronchiolitis is primarily caused by viral pathogens, the use of antibiotics should not be administered, but due to the concern about secondary bacterial infections, antibiotics may be unwittingly given during this illness. Studies have shown no benefit in the use of antibacterial agents for the treatment of bronchiolitis and also have demonstrated low rates of secondary bacterial infections in patients with bronchiolitis; when a secondary bacterial infection did occur, it was more likely to be related to a urinary tract infection than other sources. ${ }^{13}$ Bacterial pneumonia in infants with bronchiolitis without consolidation is not a usual occurrence. Despite this, about $25 \%$ of hospitalized infants with bronchiolitis will have radiographic evidence of infiltrates or atelectasis commonly mistaken as a bacterial infection. ${ }^{13}$ The AAP thus recommends that antibacterial medications should only be used in children with bronchiolitis when there is definitive indication of a coexisting bacterial infection, which should be treated in the same fashion as if bronchiolitis was not present. ${ }^{13}$

Ribavirin, which is described in more detail later in this review, is an antiviral therapy with a complex delivery system and high cost. Despite this, its efficacy has been controversial, as shown in a number of studies with conflicting results. ${ }^{13}$ Therefore, the AAP does not recommend the routine use of ribavirin in children with bronchiolitis.

Finally, palivizumab prophylaxis to confer passive immunity against RSV during the RSV season is recommended for selected infants and children with chronic lung disease, history of prematurity ( $<35$ weeks gestation), or with congenital heart disease, and it is generally given in 5 monthly doses, usually starting in November. ${ }^{13}$ This vaccine will be described in detail in the following section.

As is evident, there are no true established therapies for bronchiolitis, with most treatments falling into the realm of supportive care once diagnosis has been made and others needing to be individualized to each patient, based on clinical benefit.

\section{Preventative/vaccination}

\section{Palivizumab}

RSV preventative measures are an ideal priority for patients who are at the highest risk of complications. Palivizumab is a humanized monoclonal antibody specifically targeting one of the RSV proteins. It is active against both A and B subtypes of $\mathrm{RSV},{ }^{14}$ and can be administered either intramuscularly 
or intravenously. While palivizumab has been extensively studied in the setting of RSV prophylaxis, limited literature is available addressing its use for treatment. One systematic review evaluated the outcomes when palivizumab was used for the treatment of both upper and lower respiratory tract infections. When clinical outcomes were compiled, three of $25(12 \%)$ patients with upper respiratory tract infections who were given palivizumab died of RSV, and five of 88 (6\%) patients with lower respiratory tract infections who received palivizumab died of RSV. ${ }^{15}$

Most literature evaluating the potential benefits of palivizumab on RSV treatment is in the setting of immunocompromised patients, including those posttransplant or those with malignancies. A recent publication illustrates two pediatric patients with acute lymphocytic leukemia and persistent RSV infections who were successfully treated with IV palivizumab. Both patients were treated with doses of around $15 \mathrm{mg} / \mathrm{kg}$ and rapidly improved clinically after administration. ${ }^{16}$ Another study evaluated 31 pediatric patients who received IV palivizumab for the treatment of RSV between 2001 and 2005. Patient illnesses ranged from complex congenital heart disease to hematopoietic stem cell transplant, and greater than three-fourths of patients who received palivizumab also received ribavirin therapy. Seven of the 29 survivors were discharged by day 5 after RSV diagnosis and 20 survivors by day 10 after RSV diagnosis. No adverse events were reported related to palivizumab. ${ }^{17} \mathrm{~A}$ survey of current practices among the International Pediatric Lung Transplant Collaborative was published in 2012. ${ }^{18}$ This survey revealed that of the 15 centers who responded to questions regarding treatment strategies, six centers reported using palivizumab (three IV, three intramuscular). The dose reported by all centers was $15 \mathrm{mg} / \mathrm{kg}$ over the course of one day (intramuscular) or up to three days (IV). ${ }^{18}$ In adult populations, some data has also been published with regard to the utility of palivizumab in the setting of acute RSV infection. ${ }^{19}$ An adult oncology center developed a guideline to facilitate the treatment of RSV infections in hematopoietic stem cell transplant recipients. The effectiveness of these guidelines was evaluated after implementation. Between 2006 and 2008, 26 RSV-infected patients were identified. All patients received aerosolized ribavirin, and 13 patients received aerosolized ribavirin in combination with IV palivizumab. The guideline was followed in 20/26 patients (77\%). No mortality occurred within 30 days of RSV diagnosis. ${ }^{19}$

The safety of palivizumab has been evaluated in published literature for children. In 2004, a study evaluating the safety of palivizumab when given during an acute infection compared
$5 \mathrm{mg} / \mathrm{kg}$ to $15 \mathrm{mg} / \mathrm{kg}$ to placebo. ${ }^{20}$ Serious adverse events were similar between the doses tested, ranging from fever to an eye disorder. There was no evidence of exacerbation of RSV disease or negative outcomes associated with receipt of palivizumab. No immune complexes were detected on the day of the infusion or 30 days after the infusion. ${ }^{20}$ Based on the published medical literature, palivizumab is safe and should be provided to those patients who are at significant risk for RSV and related complications, with the AAP defining those patients at risk in the pediatric population.

\section{Motavizumab}

Motavizumab is a second generation monoclonal antibody derived from palivizumab. When compared to palivizumab, motavizumab was 20-fold more potent in vitro and shown to be effective at lower doses in vivo. ${ }^{21}$ During evaluation by the United States Food and Drug and Administration (FDA) in 2010, the Antiviral Drugs Advisory Committee declined licensure on the basis of safety concerns including a 3-fold increase in nonfatal hypersensitivity reactions, such as urticaria. ${ }^{22}$ However, motavizumab was approved by the European Medicines Agency for use in Europe in 2010. In a 2009 study, motavizumab was given as an IV infusion to children with RSV infection and showed no difference when comparing motavizumab to placebo in adverse effects, duration of hospitalization, or requirement of supplemental oxygen. ${ }^{23}$ However, $73 \%$ of patients who received motavizumab tested negative for the virus via nasal secretion cultures one day after administration compared to $27 \%$ of patients who received placebo. The viral load was also significantly reduced in the motavizumab group..$^{23}$ Until there is more safety and clinical efficacy data, we cannot recommend the use of motavizumab.

\section{Medi-534}

Medi-534 is a live attenuated intranasal vaccine against RSV and parainfluenza (PIV) 3. Medi-534 was found to be immunogenic and provided protection when challenged with wild-type virus in RSV and PIV3 seronegative animals (hamsters and monkeys). ${ }^{24}$ Medi-534 has also demonstrated safety in adults in a Phase I study. ${ }^{24}$ More recently, this vaccine was tested in RSV/PIV3 seropositive children aged 1-9 years and demonstrated an acceptable safety profile with these children. ${ }^{24}$ Medi-534 restricts viral replication, but was minimally immunogenic in seropositive children. Unfortunately, studies have not yielded information regarding a safe and immunogenic dosage for seronegative infants and children who would be the ideal target population. 
Further studies are needed to establish optimal immunogenic dosing and safety in seronegative infants and children; therefore, we cannot recommend the use of Medi-534.

\section{Therapeutic options}

\section{Ribavirin}

The only approved antiviral treatment of RSV by the FDA is ribavirin. Ribavirin inhibits replication of both RNA and DNA viruses, including RSV. ${ }^{25}$ This inhibition is achieved by direct (interference with RNA capping, polymerase inhibition, lethal mutagenesis) and indirect (inosine monophosphate dehydrogenase inhibition and immunomodulatory effects) mechanisms. ${ }^{18}$ Ribavirin can be administered intravenously, orally, and by aerosolization. It has often been given in combination with IV immunoglobulin (IVIG). As an aerosol, ribavirin given in experimental RSV infection was first described in 1972, ${ }^{26}$ and then studied in young adults ${ }^{27}$ and later in infants with severe RSV infection. ${ }^{28}$ There are concerns for potential teratogenicity of inhaled ribavirin particles, so safety measures are warranted, and subsequent monitoring of pulmonary function and hematologic parameters is important. ${ }^{29}$

According to a 2007 Cochrane review, four trials with 158 infants who were randomized to aerosolized ribavirin versus placebo found a statistically significant difference in mortality rate $(5.8 \%$ versus $9.7 \%$, odds ratio [OR] $0.58[0.18-1.85]) .{ }^{30}$ In three trials with 116 participants, there was a decrease in probability of respiratory deterioration $\left(7.1 \%\right.$ versus $18.3 \%$, OR 0.37 [0.12-1.18]). ${ }^{30}$ However, these studies remain underpowered to draw full conclusions. In three studies of 104 ventilated participants, the mean difference in days of hospitalization and mechanical ventilation was 1.9 days and 1.8 fewer days in the ribavirin group, respectively. ${ }^{30}$ In this meta-analysis, there were no statistically significant differences in long-term pulmonary function or incidence of recurrent wheezing following RSV infection with the use of ribavirin. ${ }^{30}$

Moreover, a significant decrease in mortality and pulmonary related morbidity due to RSV was reported in hematopoietic cell transplant recipients with aerosolized ribavirin being protective against overall and pulmonary mortality. ${ }^{31}$ However, this study was also underpowered with an $\mathrm{OR}<1$, with difficulty to replicate in larger cohorts. On a long-term basis, ribavirin was an independent factor in reducing the risk of developing asthma, asthma/recurrent wheezing, sensitization to dust mites and reduced severity of reactive airway disease and related hospitalizations..$^{30,32}$
RSV treatment strategies for infant lung transplant recipients, including ribavirin and IVIG or corticosteroids, vary at pediatric lung transplant centers ${ }^{18}$ and are reported to decrease mortality and are well tolerated, ${ }^{17}$ but comparison studies are not available. In a retrospective study, no significant differences were noted in 6-month outcomes between oral and aerosolized ribavirin therapy for RSV infection after lung transplantation. ${ }^{33}$ In five symptomatic adult lung transplant recipients with acute RSV infection, pulmonary function returned to baseline with oral ribavirin 3 to 10 months after treatment and was maintained at follow-up of 565 days with no complications or deaths. ${ }^{34}$ In their article, the authors discussed an important point of cost differences between oral and aerosolized ribavirin in those five patients, specifically $\$ 700$ versus $\$ 14,000$ for a 10 -day treatment course, respectively. ${ }^{34}$ IV ribavirin with corticosteroids has also shown to be safe and cost-effective in lung transplant recipients compared to inhaled ribavirin in lung transplant recipients. ${ }^{35}$ Oral ribavirin and corticosteroid have been well-tolerated and cost-effective therapeutic regimen in the treatment of lung and heart/lung transplant recipients. ${ }^{36}$

Safety and financial concerns often overshadow the potential benefits of ribavirin, limiting its routine clinical use. ${ }^{18,29}$ Based on the current medical literature, ribavirin is an efficacious treatment for acute RSV infection, especially in patients at risk for mortality related to the acute infection such as infants and younger children and lung transplant recipients. The patient populations that appear to benefit the most are infants with severe RSV infection leading to the need for mechanical ventilation and the infant lung transplant population. Although further research is needed, the route of administration for the specific populations should be aerosolization for those patients on mechanical ventilation and an oral form (along with corticosteroids) for pediatric lung transplant recipients.

\section{RSV-IVIG}

Significant reductions in RSV shedding from the respiratory tract following parenteral therapy with human IVIG, containing high titers of RSV-neutralizing antibodies, was noted in animal models. ${ }^{37}$ As this was well tolerated during a pilot study in infants and children, ${ }^{38}$ the natural immune response to RSV from pooled human plasma was harvested and developed into a prophylactic polyclonal hyperimmune RSV-IVIG (RespiGam; MedImmune, Gaithersburg, MD, USA).

RSV-IVIG was initially used as it provided adequate passive immunity, decreased incidence of RSV hospitalization by $41 \%-65 \%$, reduced hospital length of stay by $53 \%-59 \%$, and 
decreased the severity of infection in children $<24$ months who were born at $<35$ weeks gestation. ${ }^{39}$ However, per the RSV immune globulin study group, ${ }^{40}$ RSV-IVIG was safe but not efficacious enough in infants with bronchopulmonary dysplasia, congenital heart disease, ${ }^{41}$ or premature gestation. RSV-IVIG was cost-effective only when reserved for infants at highest risk for developing severe RSV infections and not cost-effective when used for FDA approved indications. ${ }^{42}$ RespiGam was discontinued in October 2003, as it was superseded by palivizumab in terms of potency (50 times the potency, easier administration, lack of interference with measles, mumps, rubella, and varicella vaccine, and lack of complications with IV administration of human immune globulin products). ${ }^{41}$

According to a Cochrane review published in 2010, ${ }^{43}$ the efficacy of IVIG in the treatment of RSV infection was evaluated by four prior randomized, controlled trials, with none demonstrating significant benefit in terms of mortality, length of stay, length of ventilation, oxygen dependence, pulmonary function, readmissions, and long-term respiratory issues when comparing supportive care with and without IVIG. There is likely a role for IVIG in acute RSV infection, however further research is needed. ${ }^{43}$ Affinity-purified, RSV-specific antibodies in IVIG preparations seemed to offer broad-spectrum protection to RSV-infected children during mixed infections, and further investigation is warranted. ${ }^{44}$ We cannot recommend RSV-IVIG for routine clinical use, but it may be considered on a case-by-case basis for the risk factors for individual patients.

\section{Alternative therapies Cathelicidins/vitamin D}

Cathelicidins, which are immunomodulatory cationic host defense peptides, are a key component of innate immunity, with bactericidal ${ }^{45}$ and recently identified antiviral properties, especially against influenza ${ }^{46}$ and rhinovirus. ${ }^{47}$ LL-37, the active form of the sole human cathelicidin, h-CAP-18, is expressed in neutrophils and epithelial cells, and airway epithelial cell expression of LL-37 is induced in vitro by RSV infection $^{48}$ and significantly upregulated by the $1,25(\mathrm{OH})$ metabolite of vitamin D. ${ }^{49}$

In a recent study by Currie et $\mathrm{al}^{50}$ the immunomodulatory role of human cathelicidin LL-37 against RSV and the bronchial epithelial host defenses were studied. The simultaneous exposure of LL-37 and virus resulted in significant dose-related reduction in infectivity, partly due to direct effect on the viral particles and also reduced susceptibility of the bronchial epithelial cells to infection. Also, continuous treatment of RSV-infected human epithelial cells to LL-37 resulted in significant reduction in cell apoptosis compared to untreated cells. Postexposure treatment with LL-37 showed that spread of the virus in human epithelial cells can be limited and thereby protect the intact epithelium. The antiviral activity of LL-37 is retained by a truncated peptide fragment, which opens the possibility of development of shorter peptide analogs, which may enable development of newer therapeutic interventions for RSV. Current therapeutic innovations are directed towards enhancing LL-37 expression with drugs such as butyrate and/or vitamin D supplementation. 4-Phenylbutyrate has been shown to upregulate h-CAP-18/ LL-37 expression in human airway epithelial cells in vitro, especially when acute short-term upregulation is required. ${ }^{51}$ Thus, modulation of cathelicidin expression with upregulation by vitamin $\mathrm{D}$ raises the potential of development of synthetic peptide analogs for use in postexposure RSV prophylaxis. This is a therapeutic option in development that is clearly showing some promise in current studies.

A meta-analysis of existing literature on vitamin D receptor polymorphisms supports an association between the Fokl vitamin D receptor polymorphism and RSV severity. ${ }^{52}$ This is in addition to studies of cord blood vitamin D levels which demonstrate that birth 25 -hydroxy vitamin D concentrations $<50 \mathrm{nmol} / \mathrm{L}$ increase the risk of $\mathrm{RSV}$ in the first year of life by sixfold. ${ }^{53}$ Subsequent vitamin D intervention studies, such as the pediatric randomized trial in Mongolia, have shown the ability of vitamin D to reduce acute respiratory events. ${ }^{54}$ However, a specific reduction in RSV incidence has not been delineated to date. Further work is also needed to determine the impact of vitamin D on RSV prevention in all children, including those patients with deficiency of this fat soluble vitamin.

\section{Pre- and probiotics}

The role of the gut microbiota in preventing respiratory infections and modulating immune responses has been the focus of many recent studies. Specifically, prebiotic and probiotic supplementation in a preterm infant population (32 to 36 weeks) has been shown in a randomized trial to reduce the incidence of viral respiratory tract infection in comparison to placebo. ${ }^{55}$ The study population had a much higher incidence of rhinovirus compared to RSV, but these findings suggest a potential preinfection intervention strategy for premature infants. It is unclear if this same strategy would be applicable to full-term and older infants, as another recent study in a daycare population with probiotics has only shown a reduction in symptom days, without a reduction 
in RSV incidence. ${ }^{56}$ Irrespective, modifying RSV disease incidence in premature infants with a relatively cheap and available option such as probiotics would be more easily implemented worldwide than most current expensive and resource-heavy strategies. Although further studies are needed to better define the role of prebiotics and probiotics for RSV infection, they appear not to be associated with any significant adverse events.

\section{Curcumin}

Naturally occurring substances such as curcumin may provide protection in RSV acquisition. Curcumin ([1E,6E]1,7-bis[4-hydroxy-3-methoxyphenyl]-1,6-heptadiene-3,5dione) is a principle component of the spice turmeric and is responsible for the bright yellow color in curried dishes. Curcumin has pleiotropic effects in the body including antiinflammatory, anticancer, antiviral, and autophagy manipulation. ${ }^{57,58}$ Recently Obata et al demonstrated the effects of preinfection curcumin treatment on preventing RSV replication in human nasal epithelial cells with little cytotoxicity. ${ }^{59}$ However, there was minimal effect on lung epithelial cells, suggesting that curcumin would work best as a preventative therapy to lessen disease acquisition and severity. While few side effects exist with curcumin supplementation, the exact route and dose needed for RSV prevention in children would still need to be determined, as RSV is still prevalent in areas such as India with extensive turmeric use. ${ }^{60}$ The use of curcumin as a potential preventative treatment of RSV is intriguing, but it cannot be recommended for clinical use until further research identifies benefit for patients.

\section{Modified dingchuan decoction}

Modified dingchuan decoction (MDD) is a mixed formulation of the Chinese herbs Salviae miltiorrhizae radix, Scutellariae radix, Farfarae flos, and Ephedrae herba. It is anecdotally known to improve cough, asthma, pneumonia, and bronchiolitis in east China. In a murine model, MDD was shown to decrease lung histopathology, viral loads, and inflammatory mediators with low toxicity when given for 3 days. ${ }^{61}$ Additionally, in vitro analysis demonstrated a higher selectivity index against RSV than ribavirin in cell lines. ${ }^{61}$ These effects would make MDD treatment translatable to patients as a postinfection therapy to reduce the severity of symptoms. However, MDD preparations have not been tested outside of murine models in a controlled setting, and they would require rigorous methods to ensure the safety and the reproducibility of preparations without additional additives. As with other developing potential
RVS therapeutics, MDD needs further study before it can be used in humans.

\section{Conclusion}

RSV infections continue to be a significant problem worldwide, especially for infants and children, costing millions in health care expenditure. Our mainstay of therapy for RSV infection is prevention with palivizumab. Focus on vaccine development is a priority, with this single vaccine remaining our only option in a limited patient population as identified by the AAP. Newer vaccines such as Medi-534 are promising but still in the early stages of trials.

Therapy with ribavirin has proven beneficial in certain patient populations, particularly critically ill patients on mechanical ventilation and lung transplant recipients. However, the complexity and risk of aerosolization of ribavirin remain the subject of debate, especially with the equivalent outcomes with oral therapy, which significantly reduces the costs. Further research is clearly needed to directly compare the long-term efficacy of oral versus aerosolized ribavirin therapy for RSV.

Alternative therapies such as cathelicidin and MDD appear to have some promise but need further study to identify safety and dosing regimens before being used in patients. Recent findings involving probiotics, prebiotics, and vitamin $\mathrm{D}$ are appealing and would provide relatively easy and inexpensive options in children with RSV infection. If further research determines the validity of these early findings, we theorize these therapies as more complementary to standard supportive care and other various agents. Despite the promise that alternative and complementary therapies have in preventing and treating RSV, it is clear that further studies are needed to more clearly define their role and potential benefits in RSV pathogenesis.

Our therapeutic armamentarium against RSV is limited, but current research holds promise with new therapies under development and alternative options also undergoing study. As new treatments are introduced into patient care, synergistic effects with the traditional prophylactic therapies and drugs will also be needed.

\section{Disclosure}

No funding was required to complete this work. The authors report no conflicts of interest in this work.

\section{References}

1. Borchers AT, Chang C, Gershwin ME, Gershwin LJ. Respiratory syncytial virus - a comprehensive review. Clin Rev Allergy Immunol. 2013;45(3):331-379. 
2. Respiratory Syncytial Virus (RSV) Season, U.S., 2011-2012. Centers for Disease Control and Prevention. Available from: http://www.cdc. gov/features/dsrsv/. Accessed March 28, 2014.

3. Protect Against Respiratory Syncytial Virus. Centers for Disease Control and Prevention. Available from: http://www.cdc.gov/features/rsv/. Accessed March 28, 2014.

4. Stein RT, Sherrill D, Morgan WJ, et al. Respiratory syncytial virus in early life and risk of wheeze and allergy by age 13 years. Lancet. 1999;354(9178):541-545.

5. Sigurs N, Gustafsson PM, Bjarnason R, et al. Severe respiratory syncytial virus bronchiolitis in infancy and asthma and allergy at age 13 . Am J Respir Crit Care Med. 2005;171(2):137-141.

6. Kellner JD, Ohlsson A, Gadomski AM, Wang EE. Bronchodilators for bronchiolitis. Cochrane Database Syst Rev. 2000;(2):CD001266.

7. Schuh S, Canny G, Reisman JJ, et al. Nebulized albuterol in acute bronchiolitis. J Pediatr. 1990;117(4):633-637.

8. Hartling L, Wiebe N, Russell K, Patel H, Klassen TP. Epinephrine for bronchiolitis. Cochrane Database Syst Rev. 2004;(1):CD003123.

9. Patel H, Platt R, Lozano JM, Wang EE. Glucocorticoids for acute viral bronchiolitis in infants and young children. Cochrane Database Syst Rev. 2004;(3):CD004878.

10. Garrison MM, Christakis DA, Harvey E, Cummings P, Davis RL. Systemic corticosteroids in infant bronchiolitis: a meta-analysis. Pediatrics. 2000;105(4):E44.

11. Respiratory Syncytial Virus Infection (RSV). Centers for Disease Control and Prevention. Available from: http://www.cdc.gov/rsv/research/ us-surveillance.html. Accessed March 28, 2014.

12. American Academy of Pediatrics Subcommittee on Diagnosis and Management of Bronchiolitis. Diagnosis and management of bronchiolitis. Pediatrics. 2006;118(4):1774-1793.

13. Johnson S, Oliver C, Prince GA, et al. Development of a humanized monoclonal antibody (MEDI-493) with potent in vitro and in vivo activity against respiratory syncytial virus. J Infect Dis. 1997;176(5): 1215-1224.

14. Hu J, Robinson JL. Treatment of respiratory syncytial virus with palivizumab: a systematic review. World J Pediatr. 2010;6(4): 296-300.

15. Santos RP, Chao J, Nepo AG, et al. The use of intravenous palivizumab for treatment of persistent RSV infection in children with leukemia. Pediatrics. 2012;130(6):e1695-e1699.

16. Chávez-Bueno S, Mejías A, Merryman RA, AhmadN, Jafri HS, Ramilo O. Intravenous palivizumab and ribavirin combination for respiratory syncytial virus disease in high-risk pediatric patients. Pediatr Infect Dis J. 2007;26(12):1089-1093.

17. Danziger-Isakov LA, Arslan D, Sweet S, Benden C, Goldfarb S, Wong J. RSV prevention and treatment in pediatric lung transplant patients: a survey of current practices among the International Pediatric Lung Transplant Collaborative. Pediatr Transplant. 2012;16(6):638-644.

18. McCoy D, Wong E, Kuyumjian AG, Wynd MA, Sebti R, Munk GB. Treatment of respiratory syncytial virus infection in adult patients with hematologic malignancies based on an institution-specific guideline. Transpl Infect Dis. 2011;13(2):117-121.

19. Sáez-Llorens X, Moreno MT, Ramilo O, Sánchez PJ, Top FH, Connor EM; MEDI-493 Study Group. Safety and pharmacokinetics of palivizumab therapy in children hospitalized with respiratory syncytial virus infection. Pediatr Infect Dis J. 2004;23(8):707-712.

20. Wu H, Pfarr DS, Johnson S, et al. Development of motavizumab, an ultra-potent antibody for the prevention of respiratory syncytial virus infection in the upper and lower respiratory tract. $J$ Mol Biol. 2007;368(3):652-665.

21. Lowry F. FDA panel nixes licensing request for motavizumab [webpage on the Internet]. New York, NY: Medscape; 2010. Available from: http:// www.medscape.com/viewarticle/722903. Accessed January 10, 2014.

22. Lagos R, DeVincenzo JP, Muñoz A, et al. Safety and antiviral activity of motavizumab, a respiratory syncytial virus (RSV)-specific humanized monoclonal antibody, when administered to RSV-infected children. Pediatr Infect Dis J. 2009;28(9):835-837.
23. Gomez M, Mufson MA, Dubovsky F, Knightly C, Zeng W, Losonsky G. Phase-I study MEDI-534, of a live, attenuated intranasal vaccine against respiratory syncytial virus and parainfluenza-3 virus in seropositive children. Pediatr Infect Dis J. 2009;28(7):655-658.

24. Ribavirin aerosol approved for severe cases of RSV in infants and young children. FDA Drug Bull. 1986;16(1):7.

25. Sidwell RW, Huffman JH, Khare GP, Allen LB, Witkowski JT, Robins RK. Broad-spectrum antiviral activity of Virazole: 1-beta-D-ribofuranosyl1,2,4-triazole-3-carboxamide. Science. 1972;177(4050):705-706.

26. Hall CB, Walsh EE, Hruska JF, Betts RF, Hall WJ. Ribavirin treatment of experimental respiratory syncytial viral infection. A controlled double-blind study in young adults. JAMA. 1983;249(19):2666-2670.

27. Ribavirin for severe RSV infection. $N$ Engl J Med. 1991;325(26): 1884-1886.

28. Krilov LR. Safety issues related to the administration of ribavirin. Pediatr Infect Dis J. 2002;21(5):479-481.

29. Ventre K, Randolph AG. Ribavirin for respiratory syncytial virus infection of the lower respiratory tract in infants and young children. Cochrane Database Syst Rev. 2007;(1):CD000181.

30. Waghmare A, Campbell AP, Xie H, et al. Respiratory syncytial virus lower respiratory disease in hematopoietic cell transplant recipients: viral RNA detection in blood, antiviral treatment, and clinical outcomes. Clin Infect Dis. 2013;57(12):1731-1741.

31. Edell D, Khoshoo V, Ross G, Salter K. Early ribavarin treatment of bronchiolitis: effect on long-term respiratory morbidity. Chest. 2002;122(3):935-939.

32. Li L, Avery R, Budev M, Mossad S, Danziger-Isakov L. Oral versus inhaled ribavirin therapy for respiratory syncytial virus infection after lung transplantation. J Heart Lung Transplant. 2012;31(8):839-844.

33. Pelaez A, Lyon GM, Force SD, et al. Efficacy of oral ribavirin in lung transplant patients with respiratory syncytial virus lower respiratory tract infection. J Heart Lung Transplant. 2009;28(1):67-71.

34. Glanville AR, Scott AI, Morton JM, et al. Intravenous ribavirin is a safe and cost-effective treatment for respiratory syncytial virus infection after lung transplantation. J Heart Lung Transplant. 2005;24(12): 2114-2119.

35. Fuehner T, Dierich M, Duesberg C, et al. Single-centre experience with oral ribavirin in lung transplant recipients with paramyxovirus infections. Antivir Ther. 2011;16(5):733-740.

36. Hemming VG, Prince GA, Horswood RL, et al. Studies of passive immunotherapy for infections of respiratory syncytial virus in the respiratory tract of a primate model. J Infect Dis. 1985;152(5):1083-1087.

37. Hemming VG, Rodriguez W, Kim HW, et al. Intravenous immunoglobulin treatment of respiratory syncytial virus infections in infants and young children. Antimicrob Agents Chemother. 1987;31(12): $1882-1886$.

38. SandritterTL, Kraus DM. Respiratory syncytial virus-immunoglobulin intravenous (RSV-IGIV) for respiratory syncytial viral infections: part I. J Pediatr Health Care. 1997;11(6):284-291; quiz 292.

39. Rodriguez WJ, Gruber WC, Welliver RC, et al. Respiratory syncytial virus (RSV) immune globulin intravenous therapy for RSV lower respiratory tract infection in infants and young children at high risk for severe RSV infections: Respiratory Syncytial Virus Immune Globulin Study Group. Pediatrics. 1997;99(3):454-461.

40. Prevention of respiratory syncytial virus infections: indications for the use of palivizumab and update on the use of RSV-IGIV. American Academy of Pediatrics Committee on Infectious Diseases and Committee of Fetus and Newborn. Pediatrics. 1998;102(5):12111216.

41. Barton LL, Grant KL, Lemen RJ. Respiratory syncytial virus immune globulin: decisions and costs. Pediatr Pulmonol. 2001;32(1):20-28.

42. Fuller HL, Del Mar CB. Immunoglobulin treatment for respiratory syncytial virus infection. Cochrane Database Syst Rev. 2006;(4):CD004883.

43. Gupta N, LeGoff J, Chamat S, et al. Affinity-purified respiratory syncytial virus antibodies from intravenous immunoglobulin exert potent antibody-dependent cellular cytotoxicity. PLoS One. 2013;8(7):e69390. 
44. Kovach MA, Ballinger MN, Newstead MW, et al. Cathelicidin-related antimicrobial peptide is required for effective lung mucosal immunity in Gram-negative bacterial pneumonia. J Immunol. 2012;189(1): 304-311.

45. Barlow PG, Svoboda P, Mackellar A, et al. Antiviral activity and increased host defense against influenza infection elicited by the human cathelicidin LL-37. PLoS One. 2011;6(10):e25333.

46. Mansbach JM, Piedra PA, Borregaard N, et al. Serum cathelicidin level is associated with viral etiology and severity of bronchiolitis. J Allergy Clin Immunol. 2012;130(4):1007-1008. e1.

47. Hansdottir S, Monick MM, Hinde SL, Lovan N, Look DC, Hunninghake GW. Respiratory epithelial cells convert inactive vitamin D to its active form: potential effects on host defense. J Immunol. 2008;181(10):7090-7099.

48. Yim S, Dhawan P, Ragunath C, Christakos S, Diamond G. Induction of cathelicidin in normal and CF bronchial epithelial cells by 1,25-dihydroxyvitamin D(3). J Cyst Fibros. 2007;6(6):403-410.

49. Currie SM, Findlay EG, McHugh BJ, et al. The human cathelicidin LL-37 has antiviral activity against respiratory syncytial virus. PLoS One. 2013;8(8):e73659.

50. Steinmann J, Halldórsson S, Agerberth B, Gudmundsson GH. Phenylbutyrate induces antimicrobial peptide expression. Antimicrob Agents Chemother. 2009;53(12):5127-5133.

51. McNally JD, Sampson M, Matheson LA, Hutton B, Little J. Vitamin D receptor (VDR) polymorphisms and severe RSV bronchiolitis: a systematic review and meta-analysis. Pediatr Pulmonol. Epub September 9, 2013.

52. Belderbos ME, Houben ML, Wilbrink B, et al. Cord blood vitamin D deficiency is associated with respiratory syncytial virus bronchiolitis. Pediatrics. 2011;127(6):e1513-e1520.

53. Camargo CA, Ganmaa D, Frazier AL, et al. Randomized trial of vitamin D supplementation and risk of acute respiratory infection in Mongolia. Pediatrics. 2012;130(3):e561-e567.
54. Luoto R, Ruuskanen O, Waris M, Kalliomäki M, Salminen S, Isolauri E. Prebiotic and probiotic supplementation prevents rhinovirus infections in preterm infants: a randomized, placebo-controlled trial. JAllergy Clin Immunol. Epub October 13, 2013.

55. Kumpu M, Lehtoranta L, Roivainen M, et al. The use of the probiotic Lactobacillus rhamnosus GG and viral findings in the nasopharynx of children attending day care. J Med Virol. 2013;85(9):1632-1638.

56. O’Sullivan-Coyne G, O’Sullivan GC, O’Donovan TR, Piwocka K McKenna SL. Curcumin induces apoptosis-independent death in oesophageal cancer cells. Br J Cancer. 2009;101(9):1585-1595.

57. Aggarwal BB, Harikumar KB. Potential therapeutic effects of curcumin, the anti-inflammatory agent, against neurodegenerative, cardiovascular, pulmonary, metabolic, autoimmune and neoplastic diseases. Int J Biochem Cell Biol. 2009;41(1):40-59.

58. Obata K, Kojima T, Masaki T, et al. Curcumin prevents replication of respiratory syncytial virus and the epithelial responses to it in human nasal epithelial cells. PLoS One. 2013;8(9):e70225.

59. Choudhary ML, Anand SP, Wadhwa BS, Chadha MS. Genetic variability of human respiratory syncytial virus in Pune, Western India. Infect Genet Evol. 2013;20:369-377.

60. Li L, Yu CH, Ying HZ, Yu JM. Antiviral effects of modified dingchuan decoction against respiratory syncytial virus infection in vitro and in an immunosuppressive mouse model. J Ethnopharmacol. 2013;147(1): $238-244$.

61. Villenave R, Thavagnanam S, Sarlang S, et al. In vitro modeling of respiratory syncytial virus infection of pediatric bronchial epithelium, the primary target of infection in vivo. Proc Natl Acad Sci USA. 2012;109(13):5040-5045.
ClinicoEconomics and Outcomes Research

\section{Publish your work in this journal}

ClinicoEconomics \& Outcomes Research is an international, peerreviewed open-access journal focusing on Health Technology Assessment, Pharmacoeconomics and Outcomes Research in the areas of diagnosis, medical devices, and clinical, surgical and pharmacologica intervention. The economic impact of health policy and health systems

\section{Dovepress}

organization also constitute important areas of coverage. The manuscript management system is completely online and includes a very quick and fair peer-review system, which is all easy to use. Visit http://www.dovepress.com/testimonials.php to read real quotes from published authors. 